\title{
Digital Exclusion or Digital Choice: Exploring the Gaps, Conflicting Views and Actions About E-Inclusivity - A Case of FE Lecturers
}

\author{
Anietie G. Ukpabio \\ 1.Doctoral Researcher of PhD in E-Research and Technology Enhanced Learning Lancaster University. \\ Lancaster, UK \\ 2.Business Analyst at IBM Client Innovation Centre. Leicester, UK
}

\begin{abstract}
This exploratory study explored the attitudes, opinions and perceptions of further education lecturers about einclusion. The use of a thematic literature review approach was deployed towards reviewing within and between relevant and related literature. A case study method was used to collect data in the forms of observing four lesson sessions and interviewing six further education practitioners (which was made up of four lecturers and two learning support assistants), all within the case and context of a further education college. A qualitative data analysis technique was deployed and the results and findings of the study involved staff resistance to, lack of time, lack of literacy and numeracy skills insufficient know-how, lack of training and most importantly, lack of parental support.
\end{abstract}

Keywords: E-inclusion, exclusion, inclusivity, exclusivity, ICT, learning technology, classroom, learner support, learner engagement

DOI: $10.7176 / \mathrm{JEP} / 10-10-01$

Publication date: April $30^{\text {th }} 2019$

\section{Introduction}

Inclusion is the act that compels academic institutions to make necessary adjustments that would accommodate learners with diverse learning styles and challenges and treat them equally while they engage in learning. However, having stated that, it is arguably surprising that academic policy makers were able to arrive so quickly at the correct model of making all learners part of a learning system (inclusiveness), such as pushing the tendency to orient the lecturers and notation around knowledge sharing (Tamim et al., 2011). Inclusion in this state is a complex goal to achieve, it is a contention that as technology continues to involve and evolve in the field of learning, the dynamics of learning is not only altered as inclusion extends to e-inclusion which arguably later generates an alternative reality that is co-constructed and re-co-constructed by the lecturers, and coexists only to create a conceptual imbalance among the learners and lecturers (Jean, 2010).

Given the aim to explore the parallel realities of e-inclusion in the context of blended learning and elearning, due to the fact that these competing prime and alternative realities of e-inclusion are widely shaped by the perceptions, opinions and attitudes of the lecturers who are often mostly charged with the mandate of making "one-coat-for-all" or one solution fits all, it quickly became the focus of this study to seek to understand more deeply the foundation from which the driving forces of these realities emerged (Seale et al, 2010).

Using a limited range of experience gained from mingling and working in a further education (FE) college where technology is hugely utilised in teaching, a contention is at this moment set in that the practical meaning and purpose of e-inclusion is subjectively-relative (unique to every lecturer and not properly conceived) to each lecturer. It is often a case where lecturers debate either practically or conceptually towards defending that their teaching and or assessment styles work best towards including students and quite often opens up the learners towards struggling to adapt to a myriad education and assessment styles which led to the materialization of characteristically colourful words termed "the act being inclusively-excluded".

To sum it all up, this paper focuses on e-inclusion in the case of how lecturers in a selected FE college utilise technology in their lessons; a principal within the case are the conceptual questions of what e-inclusion means to the lecturers and what they wished it were, all towards an e-inclusive learning practice.

\subsection{Study assumptions}

Principal assumptions are one of the fundamental elements that trigger the thoughts that led to this research. Whilst this study firmed up on a constructivist point of view (the researcher's view), there exist traces of positivist and interpretivist views that whilst overlapping, may not be necessary to highlight but yet helped towards the emergence of some principal assumptions that are made not by its plausibility but by the amount of thoughts that can be triggered (Tuli, 2011; Davoudi, 2012).

Principal among these assumptions is that which states that the quest to forcibly understand and resonate with the ideation of e-inclusion often gives rise to the birth of an alternative reality that co-exists competitively 
with the prime reality of e-inclusion. Furthermore, these realities further manifest as subjective to each lecturer and generates pedagogy and curriculum imbalance at both the learners' and lecturers' ends of the interaction spectrum.

\subsection{Study questions}

What are FE college lecturers' attitudes, perceptions, and opinions towards e-Inclusive education?

\section{Review of relevant literature}

A significant quantity of literature has been written and published about the achievements and disappointments of e-inclusion. An important part of this literature has been prone to fall into one of two groupings. The primary and larger group may be expressed as 'factorial analysis'. Factorial analysis includes taking a case or a survey of cases, which often ponders on classifying the issues that obstructs the achievement of e-inclusion (e.g. Andreasson, 2015; Beacham \& McIntosh, 2014; Guldberg, et al., 2013; Michailidou et al., 2012; Niehaves et al., 2010; Ruohonen et al., 2013; Vitolina \& Kapenieks, 2013; Whitney et al., 2011; Yim et al., 2015).

It is vital to state that this literature has been valuable in building the general body of understanding from which this research builds; there are divides and inconsistencies which were explored as a measure of gaining understandings about "what did not work" or "what won't work." Most of this literature is apt towards circumstances rather than performance and characteristics, and rather than using the method which addresses the flaws; they focus on the flaws of e-inclusion. In situations where suggestions centred on performances were given, such proposals have arguably for the most part been inflexible and normative. Moreover, this appears to make the literature emerging weak and annulled of the theoretical underpinnings or even models that would convincingly allow generalisation.

The second group is a small classification of work endeavouring highly essential theory advancement, distinctively on the premise of the theory of inclusion which was supported by the Salamanca statement of 1994 which was signed by 92 governments and 25 international organisations. They are regularly expanding a student's engagement by eradicating obstacles (which may be unstructured, organized, natural, or attitudinal) (e.g. Jean, 2013; Pautasso et al., 2011; Nita, 2011; Huang and Huang, 2011; Bocconi and Ott, 2011; Lytras et al., 2013; Seale et al., 2010; Vitolina, 2015). This work is mostly suited for policy makers in academic institutions in framing the ideation of a standard that would accommodate most academic establishments. Those in charge of the common inclusion failure have repeatedly discovered complexity in the comprehension of the insinuation from this category of literature.

Through an examination of the issues, this study endeavours to plot a 'third-way' or a 'middle ground' that lies in between the two specified groups with the viewpoint of conceivably gaining some cognitive clues that can provide some understanding on what the sentiments, opinions and the state of mind of FE college lecturers hold on e-inclusion and their role in obstacles to e-inclusion and in relation it to e-inclusion politics, global pressures on e-inclusion, and the special educational needs (SEN) industry.

\subsection{Inclusion, Society and Technology}

Inevitably, to date, hypothesis, studies, educational practices and policies in social inclusion have had a tendency to trail in the form of 'parallel lines'. Although it has for some time been perceived that training (or the absence of it) is inevitably connected to the situation and end results of social exclusion, minimal and inefficient work has been done to build a 'reinforced' way to deal with learning and inclusion and to coordinate these areas with other associated approaches, for example, nationality, identity, immigration and society restoration or in a more harsh term - damage control (Monje and del Olmo, 2010). Furthermore, the significance is in connection with the implementation and utilisation of new advancements in education which are especially targeted towards disadvantaged groups as there are expanding proofs that innovations might work to boost as opposed to diminishing imbalances and encourage as opposed to eliminating the alleged digital-divide (Seale et al., 2010).

Another category of issues oscillates around the emergence of modern technologies into some types of social associations and social dialogues - and more significantly, the role of innovations in technologies in determining new kinds of social partnerships and interactions. These issues and the driving forces that propel them are quickly developing and are profoundly challenged. More specifically and coherently, there exists a viewpoint that sturdily deems that the procedure of globalization is making social orders in which individuals' stages of admission to data and information are turning into a significant factor in deciding their admittance into monetary, social and political domains. Those lacking admission to "authority" understanding and data are progressively rejected from noteworthy involvement in the society. Since the rejected are less inclined to have the capacity to get to new advancements, then it is exceedingly likely that they are an embodiment of most of the rising 'computerized underclass' (Spada, 2014).

The opposing perspective to this point of view is that new technological advancements can emerge with solutions to social exclusion through, for instance, giving admission to the directly and indirectly prohibited and 
'difficult to reach' as well as opportunities. Possibly more fundamentally, there is a contention that modern technology gives chances to the progression of numerous characters and the constant re-definition and redevelopment of "themselves" (Giddens, 1991; 1994; Hensler et al., 2000).

\subsection{Thinking within and Beyond the Lecturers and Technology}

In relation to the arguably trivial inabilities of lecturers to adapt to technological advancements, a contention is at this moment set in that educational technology, and data-driven innovation assumes a vital part in making a viable and versatile learning atmosphere, particularly when teaching students with special education needs and inclusive learning environments. Nevertheless, the utilisation of information and communication technology (ICT) in teaching students with special education needs has to date been insufficient in ways that suggests that most equipment and programming is intended for the standard populace and does not give careful consideration to an extensive variety of capacities and individuals with disabilities (Wu, et al., 2013). Furthermore, amid the plethora of resources that simplifies e-inclusion in e-learning, there is an absence of key voices that represents the learners, parents, disabled people, minority groups and lecturers who can help towards understanding the viable approach of amalgamating technology with learning (Tomlinson, 2012; Strathern, 2014).

Notwithstanding the immediate importance on e-inclusion has empowered much enthusiasm for utilizing different ICT applications for incorporating pupils with disabilities into the standard school environment, the review of existing literature shows an absence of thoughtfulness regarding the use of ICT for individuals with special education needs (Sunthonkanokpong, 2011). ICT for students with special education needs helps distinctive sorts of inabilities with assistive technology (Dell et al., 2011). The primary fissure is inside improvement of learning situations and frameworks which encourage the inclusion of people with various sorts of inabilities. Lecturers are not exceedingly attentive to learning surroundings (either blended or e-learning) and their possibilities for individualized learning directions, analytical surroundings, shared/collective learning and encouraging social attitudes, individualized learning arrangement, and appropriate support for pupils with disabilities in the e-inclusive classroom. Research studies demonstrate that the utilization of online correspondence by youngsters has turned into a most regular action, along with the web and virtual environment which has been incorporated in the youngsters' lives, where youngsters with disabilities are helpless and underestimated (McLeskey et al., 2012; Kelly et al., 2011).

Preparing lecturers for the new academic roles and responsibilities, including the utilization of ICT in educating and learning and in building up their proficient abilities, is a need embodied inside the European Union (EU) and national guidelines (Tas, 2010). Skills in utilizing ICT (Livingstone, 2012) in a lecturer's area of expertise and learning represents one of the fundamental drivers of progress while making effective learning environments and pertaining new ways to handle teaching (Anderson, 2010). Some studies have demonstrated that the introduction of new technology into real learning contexts has been moderate in advancement, in which there is a caution of an inconsistency between the development targets and the present level of ICT addition (Wastiau et al., 2013). Two particular studies led by lecturers in Australian and Dutch primary schools demonstrated that the coordination of ICT was executed utilizing the customary methodologies which neglected to realize changes in ways to deal with learning which would be obligatory to keeping in mind the end goal to set up effective ICT aided learning environments (Sarkar, 2012; Scheuermann et al., 2010).

A lecturer's individual orientations, ideologies and also the technology associated stance are mostly connected to self-productivity (Zhou et al., 2010) in the acknowledgment of technology process, ICT encounters (Kreijns et al., 2013) and are prerequisites for choices and activities on proficient learning, career developments, and change. To gauge the effects of lecturers' training, the emphasis is on the impact of training on the lecturers' mentalities, self-viability, satisfaction, value, and behavioural goal towards the utilization of the web and or the ICT medium (Mahmud and Ismail, 2010).

With regards to lecturer training, the requirement for a movement from specialized capabilities to skills in guiding one's own expert progress is required (Teo, 2010), keeping in mind that the end goal is to prepare lecturers to react to changes and joining advancement in teaching (Hernández-Ramos et al., 2014).

Proficient growth in ICT needs to address proficient needs and societies and not principally concentrate on preparing for ICT attitudes (Farrukh and Singh, 2014; Hernández-Ramos et al., 2014).

Elsaadani (2013) stated that "Lecturers refer to the inadequacy of time, inadequate understanding of the pedagogical exploit of technology, and the lack of know-how on current software as three unique obstacles to utilising technology. Lecturers and support staff need fragmentary training keeping in mind that the end goal is to reach knowledgeable verdicts in regards to the technological aspects, including the needs of all pupils and those who have special needs".

Attitudinal and relevant actuality is connected with a typical college-wide education classroom that may influence the achievement or disappointment of e-inclusion (Tezci, 2011). Tamim et al.'s (2011) study demonstrated that the wide range of education classrooms was a spot where indifferent, batch information, as opposed to granular information and lecturers, were more worried and focused on keeping up the schedule than 
meeting individual learners' needs. They contended that "lecturers thought about young learners and were overly concerned about their job security to the extent that their mentality was about transparency, not convenience. In this situation (normal education classes), learners who could not obey rules or keep up with the required pace of transparency act were predictably going to be unsuccessful." Ott et al. (2010) had a similar response when they investigated an analogous situation for learners with disabilities in the classroom. Irrespective of the expected dissimilarity of teaching and assessment methods for both learners with difficulties and those without, there were no special treatments.

In the contexts of underdeveloped and developing countries, the main limitation towards the adoption of inclusive education is that inclusive approaches in education is due to genuine inadequacy of resources, for example, absence of schools or insufficient resources, absence of lecturers and/or lack of experienced employees, absence of learning resources and lack of encouragement (UNESCO, 2003). Routine lecturers are not satisfactorily trained to give broadened teaching strategies or to adapt to the requirements of different learners.

On the other hand, moving in the direction of inclusive strategies in education in developing countries is done regularly because of the legacy of conventional guidelines and practices, for example, isolated or restricted education for learner groups who are recognized as being "dissimilar" or "diverse" or categorised by societal affluence, faith, and other related factors. The dual frameworks of education have existed globally especially in countries that are developed, and this creates a standard education framework that ceases to provide for young learners who could dispute its conventionality, composition or execution and different and unique schools and lessons for a specific collection of learners, for example, learners with disabilities, learners from various ethnicities, learners with reproachful conducts, and so forth. The set-up is additionally reinforced by unique motivating enticement for lecturers who work in the SEN industry; for example, better income, lower retirement age and smaller classes which obstruct endeavours in altering the processes of the framework (Isaacs et al., 2013).

\subsection{The Issues with the Pedagogy}

Pedagogically, the significance of specialised interference and the understanding required by lecturers to execute and keep up communicating socially would encourage the method or act of inclusion. "Having course resources online, the student's position alters fundamentally from a beneficiary to becoming a co-facilitator. Because the lecturer will be required to study new resources, the students will likewise need to study new resources to take full advantage of the globally available resources and information online" (Della Volpe, 2012). Furthermore, concerns regarding the readiness of pupils should be dealt with to permit them to have the capacity to connect efficiently and not to withdraw as a result of technology and social-related barriers.

Numerous students are rejected from taking part in schools due to their social, family/ethnic and financial status, and the students or group may not fully resonate or come to terms with the idea of studying distantly (Beacham, 2011). Distance learning materials ought to deal with the requirement for the educational method of identity (Guglielman, 2010) where different students can identify their skills and personalities in the educational programs. Beltran (2013), upheld this viewpoint by stating, "We need pupils in minority societies, dialects, and sexuality to get themselves noticed in the materials." Pupils ought to be esteemed as unique, dynamic and sensible with the energy to potentially alter theirs' and others' institutional knowledge.

Quite frequently, "in numerous settings, the educational syllabuses are broad, difficult to comprehend easily or both not collaboratively designed and inflexible allowing slight manipulability for adjustments or allowing lecturers to explore and experiment with new methodologies. The curriculum content may be too theoretical and lacking the underpinnings of learner's cognitive imagination and practice and thus not motivating to engage with. The educational syllabus may as well be sexually partial and influenced, thus promoting disengagement" (UNESCO, 2003). Consequently, the outline and growth of the particular educating and lecturing resources and lecturing schedules ought to take the requirements, learner concerns, awareness and individuality of the students into account.

\subsection{The Setup of an E-Inclusive Classroom}

Despite the fact that issues like availability, syllabus, guidelines and composition make up part of the core list of e-inclusive teaching success, societal effects linked with the broad-spectrum education situation have likewise been examined as a barrier to success. A few positive and notable social results have been discovered, essentially as improved patience as well as social backing from able learners (Beacham, 2011). On the other hand, there are still instances of natural negative outcomes that incorporate a degree of confidence, poor self-believe and insufficient social proficiency amid learners with inabilities (Lombardi et al., 2011). A bigger study scale was carried out by Lombardi et al. (2013) to evaluate the impact on inclusive acts via social structure and established that learners with inabilities were unlikely to be embraced by their co-learners, and there was a constant decline in the level of embracement over time (Shogren et al., 2015). On the whole, learners with inabilities in einclusive situations were less embraced and often perceived as redundant McCart et al. (2014). Learners who do 
not have disabilities do not have a positive mindset and better acknowledgment regarding learners with inabilities.

\section{Methodology and Method}

A primary type of research associated with the way of being or way of life and happenstances is a case study. Bruner (1986) describes a case study as "a rigorous, interconnected, portrayal of a particular occurrence, or shared belief". There are primarily three different types of case studies which are natural, influential, and joint (Yin, 2013). Although, there was a tendency based on an initial imagination to subscribe to the influential case study: the fundamental concern, however, was with studying through four lesson observations and narrative inquiries where it was deemed that the case would be for the most part introspective of this procedure. However, for a typical study of this nature, the concern that emerged was the individuality of every staff's encounter and this concern was characteristically discussed in the findings and conclusion chapter of this report. Instead of battling to unite their encounters into a broad explanation, information was gathered and investigated in a way that underlined the case and the participant's rarity.

\subsection{The Limitations of Using a Case Study Approach}

Amongst the benefits of utilising a case study approach, there are drawbacks - and a highlight will be given about the two principal drawbacks. The primary drawback falls within the category of criticism that emerges from the misinterpretation of the underpinnings of a qualitative study. The selected cases may not be the ideal fit; understandings cannot be oversimplified, justifications can be subjective, and the researchers' prejudice can affect the study. Along that line of thought, a major difficulty of this study was to thoroughly build up a comprehension of the participant's points of view and the associated happenstances while remaining totally isolated from their situation and them (Yin, 2013).

Also, the data collection and analysis techniques of phenomenography and ethnography overlap with the qualitative case study approach. Procedures, for example, building relationships and trust with participants, considering the intricacies of the circumstance and recognizing the close and short-lived variables that are affecting the participants' behaviour is difficult, and it has been vital for researchers to submerge themselves in the circumstances that they are researching. Moreover, it was significantly observed that communicating with and seeing the participants both in classroom and meeting settings was legitimate because it was the frequent interaction and communication channels of the participants that were used to discharge their professional mandates (Yin, 2013).

\subsection{Research Case Selection}

Very often, scholars involved in qualitative researches are often reliant on a case selection technique that produces a situation that encompasses all possible scenarios envisioned in their research plan (Poulis et al., 2013). For this study, the motive shifted from a "one size fits all" scenario to a situation that is greatly edifying. More specifically, the emphasis was on using a college where there was a pre-existence of some degree of participants' trust and inclination to participate. This opportunity offered a wealth of prospect to observe lessons that utilised some learning technologies. Having reviewed several kinds of literature which focused broadly on the amalgamation of technology and learning in school settings, a choice was made to select a further education college where technology was hugely utilised across all educational disciplines in co-sharing knowledge. The scope of the case was around and within e-inclusive learning activities that were conducted by FE lecturers. Four FE lecturers' lessons from science, technology, engineering and management (STEM) were observed, followed by one interview session for each lecturer and two learning support assistants. Even though at some stage of the study, unintentional interactions were made with other people who were not part of the sample, this only adds a holistic meaning to the research data.

\subsection{Collecting the Research Data}

The data gathering methods used were observation and interview, which further led to the invocation of the term 'narrative inquiry' (Xu and Connelly, 2010). The major determinants of the data collection instruments was the structure of my research question, the rarity of the underlying assumptions and presence of the cases within the selected case study. The observation phase was later re-termed as the examination phase, but this was only to serve as a reminder of what the expected outcomes of the observation session should be. A more accurate account of the examination phase involved the observation of eight lessons. During the last few days of the observation exercise, there was a serious clash in the teaching timetable that meant that the researcher who teaches most of the technology and management modules would have to miss his teaching sessions to continue the observation. That said, the only feasible solution was to reduce the observation times for the overlapping timetable sessions to thirty minutes.

The observed elements involved the kinds of technological tools that were utilised across the STEM lesson 
sessions, learners' inclination towards the use of the tools, lecturers' inclination towards the utilisation of the tools, lecturers' level of technology know-how, learners' level of satisfaction, fitness of the tools to the pedagogy and curriculum and most importantly, how learners with learning difficulties fitted in with these lessons and tools with and without the periodic help of the learning support assistants.

What followed the examination phase were the interview sessions which was coined the exploration phase, a term used only to serve as a reminder of what the outcome of this phase should be. The typical setup of the interview was designed to help trigger the capturing of individual and human proportions of occurrence over time, and was cognisance of the existence of the link between individual encounter and cultural context (Clandinin and Connelly, 2000), questions like 'can you talk about a time when teaching with technology has been challenging to you?' Even though the ways of knowing in this exploratory phase initially tended to subscribe to the pragmatic mode of thoughts which draws on rational examination, valid evidence, and pragmatic observation, there was a real shift towards narrative knowing which draws on narrative understanding - shaped, constructed, re-constructed and co-constructed using narratives of lived occurrences, and the meanings obtained, which further facilitates towards shaping the uncertainty and intricacy of human lives (Clandinin and Connelly, 2000). To sum it up, a total of six interview sessions were held, four with STEM lecturers and two with learning support assistants; two meetings lasted for about one hundred and twenty minutes each, while two meetings lasted for about thirty-five minutes each, and two sessions, which were with learning support assistants lasted for thirty minutes each. The purpose of the interviews after observations was to reach a position of data and methodological triangulation.

\subsection{Analysing the Research Data}

After the conclusion of the data collection phase which involved the notes written during observation and the audio recordings produced during the interview sessions, the event that followed was the most tedious and crucial of all research activities - data analysis. Analysing the observation data was relatively straight forward as notes had already been taken during the observation session about actions, activities and meaning creation from the settings, actions, and activities. This was followed by the interview transcripts, which were unhurriedly perused through while making notes of the first impressions. Unexcitingly, the transcripts had to be read again, carefully and serially and another set of notes were taken just to cross reference if the first impression notes varied or matched the second notes. Although, where there was dissimilarity of notes, it was only because a thematic and contextual meaning have not been associated with the first impression notes (Boyatzis, 1998). By the third read, the labelling or coding of relevant words, phrases, sentences and sections emerged. The labels were mostly about actions, activities, concepts, differences, opinions and processes.

Fundamentally, the underpinnings of the coding exercise were words and or sentences that were repeated in several places, sounded like a surprise, explicitly stated by the interviewee as important, linked to a read literature review and theories or conceptualisation of underlying patterns. Furthermore, coding generated several phenomena, most which were deemed known yet significant within the study domain - most of which are discussed in the Findings section of this report. Consequentially, the emergence of themes from the codes was seamless; the themes highlighted elements of objects, processes and differences all within the context of einclusion. Although the themes are roughly hierarchical, analysis and explanation of the themes were carried out to determine the relationships between the categories; and these relationships were what constituted the results of this study (Boyatzis, 1998).

\section{Discussion}

\subsection{Lecturers' Nostalgic Attitude to Change}

Evidentially, there were some inconsistent traces of lecturers' unwillingness to use technology in teaching during the observation sessions, but the evidence became far more consistent in the interview session as lecturers' behaviour towards independence, area of work and self-defence is a problem in colleges to some extent. Interviewees stated that a few of the lecturers were opposed to engaging with different learners who are seen to be having difficulties. There is a sense among a few lecturers that classification, selection and mediating with students with special education needs is the only obligation of the special needs professionals, particularly the learning support assistants. This mindset has a tendency to be linked to the elderly and better-qualified lecturers. A few lecturers seemed hesitant to request for extra support as stated by an associate lecturer from a further education college:

I feel it has been a challenge in the past due to the fact that there has been reluctance to accepting others in lecturers in the class are required to control what happens in their world, and if they are unable to control their world, it is a managerial challenge with the lecturer at the centre of it...lecturers do their best to cope without asking for assistance. 
Altering the way lecturer's think can be a hard method which has been acknowledged by the speaker below:

I believe it is truly difficult to adjust from old habits or to alter behaviour and views...it is a gradual procedure because training could carry on, however if people do not feel endangered...the career could come with susceptibility.

A further education lecturer who used to work in a college in a countryside area reported that the expectations of lecturers and the use of inclusion can be difficult sometimes:

...you need to target the student on where they currently stand not where you believe they need to be.

A further education college lecturer with learner support experiences recognises how expectations and considerations can become a hurdle to e-inclusion:

...having an impractical outlook or true inability to comprehend or accept that students learn in many ways, to various extents and at a different pace with different enthusiasm and achievement levels.

A lecturer's struggle with e-inclusion can be due to nervousness which is a crucial factor. Lecturers report on the nervousness of not knowing what is going on, the nervousness of feedback and nervousness of failure (Mariën and Van Audenhove, 2010; Niehaves et al., 2010). This implies that these broad factors likewise play a part in lecturers' unwillingness to bond with e-inclusive practices. The magnitude of introducing the thought that there are ample methods for doing things is reported as a challenge for lecturers with experience. Maybe the most vital element in altering a lecturer's behaviour is an accomplishment with e-inclusion (Wright and Wadhwa. 2010; Bishaw and Jayaprada, 2012).

\subsection{Lecturers' Future Worries}

A few participants believe that variety and the dominance of special educational needs amplified as the years have gone by which is a worry for further education lecturers as shown below:

I assume that when we are conversing about special needs, the option is greater now than it was in previous years... and I believe that is a test for lecturers...

According to a lecturer, uncertainties on the relevance of e-inclusion for a few of the students showed that they are reliant on the nature and extent of the incapable and/or special educational needs with a moderate learning disability, radically difficult behaviour and advanced autistic spectrum disorders which are described as alarming in the majority of schools. Most of the participants talked about their worries of involving students with essential needs that they had not come across previously as shown in the extract below:

There has not been any autistic student here, but I presume I would have been highly apprehensive had we received a request for a student with severe autism or issues with behaviour, I would say what we have got is serene....

The e-inclusion of students with major social, emotional and behavioural issues was noted as a specific issue by most of the lecturers especially the learning support assistants. The interviewees were inquisitive about whether they had the best interest of a 'socially, psychologically or behaviourally troubled student by anticipating that they would adjust and adhere to standard guidelines, schedules and policies. Similarly, the effect of e-including students with major emotional or behavioural instability with the emotional, social and educational progression of other students was seen to be a concern. These categories of issues about including students with difficult characters have been extensively discussed in the works of Wright (2010). The inclusion of the most challenging and estranged students have been described as very expensive as far as time, lecturer's stress, utilisation of external referral resources and support (which is frequently at an expense to other students). A further education college learning support assistant narrates the actual events that some lecturer's encounters:

They would utter things such as 'I do not have a clue what to do with her - I am clueless. I have tried endlessly to get her to sit on the chair or not to throw things...I am losing out and I do not have a clue what to do next...I am on the final straw.'

Although, this kind of theme was not evident during the observation session as opposed to the interview session. 


\subsection{Decline in the Quality of Initial and Subsequent Lecturer Training}

Insufficiency in undergraduate, postgraduate, and training on the job was the most named limitation in building e-inclusive learning settings. The requirement for a persistent professional growth is a theme that reoccurs in the worldwide literature on inclusion (Beacham, 2011; Guglielman, 2010). The altered position in schools with fastrising numbers of students with special educational needs was mentioned by a further education college learning support assistance as a convincing reason for comprehensive training:

...it does bring various types of issues regarding the adaptability, the approach of the learning support assistance, the group that is teaching and different strategies we usually use to sort it out, it is very different to a decade ago isn't it?

\subsection{Decline in the Quality of English Language and Mathematics}

Some respondents have stated that the obvious declining standards in general English and mathematics are making the task of inclusion harder at further education stages in which a course lecturer in a large further education college stated:

I have witnessed literacy and writing at normal levels not improve, and I have been here for eleven to ten years. Many students are coming in the first year (level one) unable to construct a sentence...the structure is created in a way where there are many writings to be completed in the courses at further education stage and examinations are mostly focused on writing.

It is evident from the investigation that lecturers are being faced with the arduous task of interacting with students who are low in achievement ranks regarding English and mathematics. This is more of an issue in the further education stage. Moreover, the variety of progress in general English and mathematics levels inside the classroom brings a tough task for diverse lecturing skills and separation.

\subsection{Time As a Barrier to Commitment}

As obvious as it may sound, time limits were repeatedly stated as an obstacle by most of the interviewees to a successful e-inclusive practice, precise timing: to plan lessons, for management, for paperwork, grading assessments, creating guidelines, staff association and teamwork which involves time for planning as a team, for selection and identification of students with special needs, for contact with guardians, relatives and other experts, to create individual schedules and courses, to fulfil the needs of the curriculum at the further education stage and to keep up with the pace of teaching courses at vocational level in further education stage. Respondents involved in the Collie et al. (2011) study agreed with this opinion, as most of the participants noted time as the main limitation in creating e-inclusive learning settings. The view that it can take a while to get to know students as individuals, to comprehend their unique needs and to put suitable intercessions in place is broadly acknowledged.

\subsection{The Need For Support From Parent and Guardians}

Including parents and support is viewed to be a significant aspect in assisting successful e-inclusive practice, an aspect which has also been disclosed in an Irish perspective by Swartz et al. (2011) and worldwide (Hornby, 2011). Social issues like inabilities, parents' separation, mistreatment, inability to read or write, compulsion, illegal behaviour, continuous failure, poverty, lack of shelter and the breakup of families are regularly shown as limitations to the inclusion of the parents (Ball, 2010). Not having support from a parent can reduce the effect of the school's involvement in learning assistance.

If the parents are difficult to reach or hard to prove a point to, then it will be unlikely that their children will be motivated e.g. it will be unlikely that their school work will be checked, but this is only possible if the student is under 18 years of age

\subsection{Digital Exclusion or Digital Choice}

It was a bit astonishing that such a theme could emerge in this study, but what was more astounding was the honest admittance of a lecturer whose attitude has become significant in making a digital choice that did seem as digital exclusion at first glance. Even though these themes were few in the sample, it is arguably assumed that there are more lecturers who share this point of view but are skeptical about sharing them primarily due to their job security.

I am not a tech kind of lecturer, all though I use it to carry out my duties but I don't like the speed at which things change in the technology world and I don't want to be into technology. Learning existed before technology, still will without technology. 


\subsection{Behavioural Challenges}

Difficult behaviour is seen as the main reason why a few pupils keep on being separated in school. Social, emotional and temperamental problems are stated to be on the rise in regards to level of seriousness, difficulty, dominance and lecturers have reported that the assistance provided in schools are insufficient, or the response takes too long as shown by a further education college lecturer:

... Challenging behaviour. . . makes it difficult for the lecturer and the provision of resources takes too long that it keeps you waiting - behaviour is solely what is excluding learners from engaging in our school.

\section{Conclusion, Recommendation And Limitations}

I have carried out an exploratory research of this nature - which has endeavoured to account for lecturers' understandings, attitudes, opinions and perceptions towards e-inclusive practices and the lecturer's view of present barriers towards setting up learning environments that are e-inclusive. Although, I faced a few challenges during the data collection and analysis phases of this study, I have managed to put forward a few findings which are presented as a premise for a much more thorough investigation of the problem inside an FE college setting. There is some evidence that lecturers agree to the standard guideline of e-inclusion. However, there are also a few doubts about the use of e-inclusion. There is a possibility of future research to build upon this study and towards exploring how the support of the guidelines for e-inclusion are used practically, especially how the opportunity for studying professionally in the colleges within the domain of e-inclusion can be encouraged (Carter et al., 2010). Furthermore, the college-centred limitations to e-inclusion distinguished in the study can be examined further which can expand on suitable approaches that can be used to reinforce the institution of einclusive learning settings (Beltran, 2013).

Universal knowledge about the use of e-inclusion has demonstrated that the complicated blend of optimistic lecturer's views mixed with worries and alleged insufficiencies found in this research is entirely normal in the progress of the use of e-inclusion in learning settings (Della Volpe, 2012). Guaranteeing that e-inclusive practice becomes the culture of further education colleges will involve lecturers re-assessing their behaviours, practices and being given the opportunity to increase their understanding professionally and their expert base. This is the issue that policy formulators and lecturers are being faced with within further education.

The idea supporting education that is e-inclusive is the fact that the procedure of inclusion could be encouraged by the introduction of modern technological apparatus which needs alterations and adjustments in the educational setting, strategies, arrangement and approaches. Lecturers have a vital responsibility in these fields: Invention cannot pass the colleges' system without meaningful and dynamic inclusion, and the educational efficiency of all technology will depend mostly on the option they choose (Sang et al., 2010). To this end, one major finding that appeared stunning was the perception that what had initially seemed like a digital exclusion or digital divide was a mere digital choice.

Consequentially, against the background of the myriad merits of not ignoring the voices of key stakeholders (like the lecturers), it is arguably possible that the involvement and efforts of the lecturers may be undermined by the continuous cycle of destruction and rebuilding idealised and re-idealised by society and technological advancements (Spada, 2014). Although, an attempt to think beyond the lecturers and the technology would imply the absolute comprehension of the 'liminality' associated to deploying e-inclusion. Such comprehension may require an almost slender paradigm shift from an instructional design to 'pedagogising' the 'liminality' of deploying e-inclusion.

Evidentially, it is worth to at least, nostalgically coming to terms with unrealistic educational policies since poor institutional standard (or the absence of it) arguably often precedes a weak policy either at the formation or enforcement stage. However, I am still unenthusiastic to reconcile with the rationality of the use of educational policies that failed to capture the voices of key stakeholders who are often charged with the mandate of enforcing or discharging the policies. This mishap often yield conceptual conflicts between the lecturers and educational policy makers - lecturers argue that the policies were 'formulated for them' rather than 'formulated with them' (UNESCO, 2003).

Significantly, regardless of the success determinants or driving forces of the fundamental list of e-inclusive teaching like syllabus, guidelines and availability; there exist social properties associated to the extensive range of educational circumstances which has equally been scrutinised as an obstacle to success. Although, there are progressive and prominent societal outcomes that has been revealed fundamentally as enhanced tolerance as well as social support from able learners (Beacham, 2011).

Conversely, there exists occurrences of normal yet undesirable results that include a degree of sureness, low self-esteem and inadequate societal aptitude amongst learners with difficulties (Lombardi et al., 2011). A greater study scale was conducted by Lombardi et al. (2013) to assess the influence on inclusive practices via social organisation and recognised that learners with difficulties were likely to be excluded by peers, and there exist a continuous deterioration in the degree of inclusion over time (Shogren et al, 2015). Overall, learners with difficulties in e-inclusive contexts were less included and habitually seeming as redundant McCart et al, (2014). 
Since learners who do not have difficulties do not have an encouraging mindset and sufficient tolerance regarding learners with inabilities, it is recommended that the alternative realities discussed in the previous chapters be eliminated and an orientation of e-inclusion be induced in the lifestyles of the lecturers and learners.

Although, to this end, I remain committed to deploying the theory of e-inclusion in my teaching practices, but my commitment currently tilts towards the ideation of pedagogising the liminality of deploying e-inclusion which I put forward as my concluding recommendation as I still believe that education in the further education sector is in a state of perilous emergency.

\section{References}

Anderson, J., (2010). ICT transforming education: A regional guide. Bangkok, TA: UNESCO.

Andreasson, K. ed., (2015). Digital Divides: The New Challenges and Opportunities of e-Inclusion (Vol. 195). CRC Press.

Ball, S.J., (2010). New class inequalities in education: Why education policy may be looking in the wrong place! Education policy, civil society and social class. International Journal of Sociology and Social Policy, 30(3/4), pp.155-166.

Beacham, N. and McIntosh, K., (2014). Student teachers' attitudes and beliefs towards using ICT within inclusive education and practice. Journal of Research in Special Educational Needs, 14(3), pp.180-191.

Beacham, N., (2011). Developing E-pedagogies for Inclusion.

Beacham, N., (2011). Developing NQTs e-pedagogies for Inclusion.

Beltran, E.V., (2013). Inclusive language education and digital technology (Vol. 30). Multilingual Matters.

Bishaw, K.S. and Jayaprada, C.L.L., (2012). Inclusive teaching in the context of english language teaching (ELT). International Journal of Physical and Social Sciences, 2(11), pp.214-228.

Bocconi, S. and Ott, M., (2011). ICT and universal access to education: Towards a culture of accessibility. In Information Systems, E-learning, and Knowledge Management Research (pp. 330-337). Springer Berlin Heidelberg.

Boyatzis, R.E., (1998). Transforming qualitative information: Thematic analysis and code development. Sage.

Carter, E.W., Sisco, L.G., Chung, Y.C. and Stanton-Chapman, T.L., (2010). Peer interactions of students with intellectual disabilities and/or autism: A map of the intervention literature. Research and Practice for Persons with Severe Disabilities, 35(3-4), pp.63-79.

Clandinin, D.J. and Connelly, F.M., (2000). Narrative inquiry.

Collie, R.J., Shapka, J.D. and Perry, N.E., (2011). Predicting teacher commitment: The impact of school climate and social-emotional learning. Psychology in the Schools, 48(10), pp.1034-1048.

Davoudi, S., (2012). The legacy of positivism and the emergence of interpretive tradition in spatial planning. Regional Studies, 46(4), pp.429-441.

Dell, A.G., Newton, D.A. and Petroff, J.G., (2011). Assistive technology in the classroom: Enhancing the school experiences of students with disabilities. Pearson Higher Ed.

Della Volpe, V., (2012). Inclusive online learning environments: Pedagogical reflections and possible applicable models. Unpublished doctoral dissertation). Foro Italico Unicersity, Italy.

Elsaadani, M.A., (2013). Exploring the Relationship between Teaching Staff Age and Their Attitude towards Information and Communications Technologies (ICT). Online Submission, 6(1), pp.216-226.

Farrukh, S. and Singh, S.P., (2014). Teachers attitude towards use of ICT in technical and non-technical institutes. Journal of Educational and Social Research, 4(7), p.153.

Giddens, A., (1991). Modernity and self-identity: Self and society in the late modern age. Stanford University Press.

Giddens, A., (1994). Beyond left and right: The future of radical politics. Stanford University Press.

Guglielman, E., (2010). E-learning and Disability: Accessibility as a Contribute to Inclusion. In EC-TEL Doctoral Consortium (pp. 31-36).

Guldberg, K., Kossivaki, L., Keay-Bright, W., Parsons, S. and Porayska-Pomsta, K., (2013). The future use of technologies in the classroom: participatory research and E-inclusion as tools to promote creativity at schools. In The European conference on educational research.

Hensler, D.R., Dombey-Moore, B., Giddens, E., Gross, J. and Moller, E., (2000). Class action dilemmas: Pursuing public goals for private gain. Rand Corporation.

Hernández-Ramos, J.P., Martínez-Abad, F., Peñalvo, F.J.G., García, M.E.H. and Rodríguez-Conde, M.J., (2014). Teachers' attitude regarding the use of ICT. A factor reliability and validity study. Computers in Human Behavior, 31, pp.509-516.

Hornby, G. and Lafaele, R., (2011). Barriers to parental involvement in education: An explanatory model. Educational Review, 63(1), pp.37-52.

Huang, C.H. and Huang, Y.T., (2011). A New Approach to Achieve e-Inclusion with ICT Education in Rural Taiwan. In Education and Management (pp. 260-268). Springer Berlin Heidelberg. 
Isaacs, J., Martinez, S., Scott-Brown, K., Milne, A., Evans, A. and Gilmour, D., (2013). Mobile technology and e-inclusion. In Universal Access in Human-Computer Interaction. Applications and Services for Quality of Life (pp. 626-635). Springer Berlin Heidelberg.

Jean, C.S., (2013). E-inclusion in early french immersion classrooms: using digital technologies to support inclusive practices that meet the needs of all learners. Canadian journal of education, 36(1), pp.44-70.

Kelly, S.M. and Smith, D.W., (2011). The impact of assistive technology on the educational performance of students with visual impairments: A synthesis of the research. Journal of Visual Impairment \& Blindness, 105(2), p.73.

Kreijns, K., Van Acker, F., Vermeulen, M. and Van Buuren, H., (2013). What stimulates teachers to integrate ICT in their pedagogical practices? The use of digital learning materials in education. Computers in human behavior, 29(1), pp.217-225.

Livingstone, S., (2012). Critical reflections on the benefits of ICT in education. Oxford review of education, $38(1)$, pp. $9-24$

Lombardi, A., Murray, C. and Dallas, B., (2013). University Faculty Attitudes toward Disability and Inclusive Instruction: Comparing Two Institutions. Journal of Postsecondary Education and Disability, 26(3), pp.221232.

Lombardi, A.R., Murray, C. and Gerdes, H., (2011). College faculty and inclusive instruction: Self-reported attitudes and actions pertaining to Universal Design. Journal of Diversity in Higher Education, 4(4), p.250.

Lytras, M.D., Ruan, D., Tennyson, R.D., Ordóñez de Pablos, P., García-Peñalvo, F.J. and Rusu, L., (2013). Information systems, e-learning, and knowledge management research.

Mahmud, R. and Ismail, M.A., (2010). Impact of training and experience in using ICT on in-service teachers' basic ICT literacy. Malaysian Journal of Educational Technology, 10(2), pp.5-10.

Mariën, I. and Van Audenhove, L., (2010), September. Embedding e-inclusion initiatives in people's daily reality: The role of social networks in tackling the digital divide. In Digitas Conference, Sibiu, Rumania.

McCart, A.B., Sailor, W.S., Bezdek, J.M. and Satter, A.L., (2014). A framework for inclusive educational delivery systems. Inclusion, 2(4), pp.252-264.

McLeskey, J.M., Rosenberg, M.S. and Westling, D.L., (2012). Inclusion: Effective practices for all students. Pearson Higher Ed.

Michailidou, E., Mavrou, K. and Zaphiris, P., (2012). May. eInclusion@ cyprus universities: provision and web accessibility. In CHI'12 Extended Abstracts on Human Factors in Computing Systems (pp. 1637-1642). ACM.

Monje, P.M.M. and del Olmo, A.M., (2010) June. Digital divide and digital citizenship: Adapting the social policies to promote e-inclusion. In ECEG2010-Proceedings of the 10th European Conference on EGovernment: National Center for Taxation Studies University of Limerick, Ireland 17-18 June 2010 (p. 251). Academic Conferences Limited.

Niehaves, B., Plattfaut, R., Gorbacheva, E. and Vages, P.H., (2010). Analysis of e-inclusion projects in Russia, Austria and Switzerland. Interactive Technology and Smart Education, 7(2), pp.72-84.

Nita, V., (2011). An extended approach to e-inclusion and its implications for Romania. Romanian Journal of European Affairs, 11(1).

Ott, M., (2010). School of the Future: E-Tools and New Pedagogies to Build. Technology Enhanced Learning for People with Disabilities: Approaches and Applications: Approaches and Applications, p.105.

Pautasso, E., Ferro, E. and Raguseo, E., (2011), June. Understanding eInclusion gaps across European regions: A benchmarking analysis. In Information Society (i-Society), 2011 International Conference on (pp. 279-286). IEEE.

Poulis, K., Poulis, E. and Plakoyiannaki, E., (2013). The role of context in case study selection: An international business perspective. International Business Review, 22(1), pp.304-314.

Ruohonen, M., Turunen, M., Linna, J., Hakulinen, J., Nanavati, A. and Rajput, N., (2013). E-Inclusion Innovation for rural India: mobile voice and tablet based educational services. In Proc. IFIP World Conference on Computers in Education (Vol. 2, pp. 218-227).

Sang, G., Valcke, M., van Braak, J. and Tondeur, J., (2010). Student teachers' thinking processes and ICT integration: Predictors of prospective teaching behaviors with educational technology. Computers \& Education, 54(1), pp.103-112.

Sarkar, S., (2012). The role of information and communication technology (ICT) in higher education for the $21 \mathrm{st}$ century. Science, 1(1), pp.30-41.

Scheuermann, F. and Pedró, F. eds., (2010). Assessing the effects of ICT in education: Indicators, criteria and benchmarks for international comparisons. Joint Research Centre-European Commission.

Seale, J., Draffan, E.A. and Wald, M., (2010). Digital agility and digital decision-making: conceptualising digital inclusion in the context of disabled learners in higher education. Studies in Higher Education, 35(4), pp.445-461. 
Shogren, K.A., McCart, A.B., Lyon, K.J. and Sailor, W.S., (2015). All Means All Building Knowledge for Inclusive Schoolwide Transformation. Research and Practice for Persons with Severe Disabilities, 40(3), pp.173-191.

Spada, K., (2014). Higher Education in the Digital Age [Book Review]. Professional Communication, IEEE Transactions on, 57(2), pp.150-153.

Strathern, M., (2014). Innovation or replication? Crossing and criss-crossing in social science. Arts and Humanities in Higher Education, 13(1-2), pp.62-76.

Sunthonkanokpong, W., (2011). Future global visions of engineering education. Procedia Engineering, 8, pp.160-164.

Swartz, T.T., Kim, M., Uno, M., Mortimer, J. and O'Brien, K.B., (2011). Safety nets and scaffolds: Parental support in the transition to adulthood. Journal of Marriage and Family, 73(2), pp.414-429.

Tamim, R.M., Bernard, R.M., Borokhovski, E., Abrami, P.C. and Schmid, R.F., (2011). What forty years of research says about the impact of technology on learning a second-order meta-analysis and validation study. Review of Educational research, 81(1), pp.4-28.

Tas, E.M., (2011). ICT education for development - a case study. Procedia Computer Science, 3, pp.507-512.

Teo, T., (2010). A path analysis of pre-service teachers' attitudes to computer use: applying and extending the technology acceptance model in an educational context. Interactive Learning Environments, 18(1), pp.65-79.

Tezci, E., (2011). Factors that influence pre-service teachers' ICT usage in education. European Journal of Teacher Education, 34(4), pp.483-499.

Tomlinson, S., (2012). A Sociology of Special Education (RLE Edu M). Routledge.

Tuli, F., (2011). The basis of distinction between qualitative and quantitative research in social science: reflection on ontological, epistemological and methodological perspectives. Ethiopian Journal of Education and Sciences, 6(1).

United Nations Educational, Scientific and Cultural Organization (UNESCO). (2003). "Underwater Cultural Heritage." Retrieved from http://www.unesco.org/new/en/culture/themes/underwater-cultural-heritage/

Vitolina, I. and Kapenieks, A., (2013). E-inclusion measurement by e-learning course delivery. Procedia Computer Science, 26, pp.101-112.

Vitolina, I., (2015). E-inclusion Modeling for Blended e-learning Course. Procedia Computer Science, 65, pp.744-753.

Wastiau, P., Blamire, R., Kearney, C., Quittre, V., Van de Gaer, E. and Monseur, C., (2013). The use of ICT in education: a survey of schools in Europe. European Journal of Education, 48(1), pp.11-27.

Whitney, G., Keith, S., Bühler, C., Hewer, S., Lhotska, L., Miesenberger, K., Sandnes, F.E., Stephanidis, C. and Velasco, C.A., (2011). Twenty five years of Training and Education in ICT Design for All and Assistive Technology. Technology and Disability, 23(3), pp.163-170.

Wright, D. and Wadhwa, K., (2010). Mainstreaming the e-excluded in Europe: strategies, good practices and some ethical issues. Ethics and Information Technology, 12(2), pp.139-156.

Wright, D., (2010). Structuring stakeholder e-inclusion needs. Journal of Information, Communication and Ethics in Society, 8(2), pp.178-205.

Wu, H.K., Lee, S.W.Y., Chang, H.Y. and Liang, J.C., (2013). Current status, opportunities and challenges of augmented reality in education. Computers \& Education, 62, pp.41-49.

Xu, S. and Connelly, M., (2010). Narrative inquiry for school-based research. Narrative Inquiry, 20(2), pp.349370.

Yim, S., Niiya, M. and Warschauer, M., (2015). e-inclusion in education: Lessons from Five Countries. Digital Divides: The New Challenges and Opportunities of e-Inclusion, 195, p.181.

Yin, R.K., (2013). Case study research: Design and methods. Sage publications.

Zhou, Q., Hu, J. and Gao, S., (2010). Chemistry teachers' attitude towards ICT in Xi'an. Procedia-Social and Behavioral Sciences, 2(2), pp.4629-4637.

Anietie Ukpabio, BSc (Hons), MSc, MBA, Cert Ed, MABE, MBCS, QTLS, FHEA I am a PhD Researcher at Lancaster University and a certified Business Analyst at IBM Client Innovation Centre.

My major interest posits in conducting research into the connections between our material surroundings, the technologies (beyond computers) that permeate them, and the ways we act, think and learn. Two recurring interests are how institutions design and evaluate their built environment domain to support opportunities for learning. More general interests include Activity Theory, networked and collaborative learning. Additionally, I also am concerned with collaborative work and group discussion in digitally-mediated environments, with a theoretical and practical commitment to social justice and equity within learning communities. I am interested in understanding the ways that sociocultural and sociotechnical elements inherent in applications of digital education operate to marginalise students who fall outside the ideations of dominant ideology.

Apart from my previous software and IT industry experience, I am also a qualified teacher and my previous 
teaching background involves being a former Computing Lecturer at East Kent College, New Vic College and City College Norwich.

My major qualifications are a first class honours degree in Computing from the University of Greenwich, an MSc. distinction in Information Technology from the Cardiff Metropolitan University, an MBA from University of Northampton.

Acknowledgement: This research was undertaken as part of the $\mathrm{PhD}$ in E-research and Technology Enhanced Learning in the Department of Educational Research at Lancaster University. I am pleased to acknowledge the contribution of lecturers and peers in supporting the development of this study and its report as an assignment paper. 